\title{
Visualization of transcription sites at the electron microscope
}

\author{
A. Trentani, ${ }^{*}$ P.S. Testillano, ${ }^{\circ}$ M.C. Risueño, ${ }^{\circ}$ M. Biggiogera* \\ * Dipartimento di Biologia Animale, Laboratorio di Biologia Cellulare, and Istituto di Genetica \\ Molecolare, University of Pavia, Italy; ${ }^{\circ}$ Laboratory of Nuclear Organization during Plant Development \\ C.I.B., Centro de Investigaciones Biológicas CSIC, Madrid, Spain
}

(C)2003, European Journal of Histochemistry

In order to localize at EM level the sites of transcription of both pre-mRNA and pre-rRNA, we have detected the DNA/RNA hybrid molecules and m3Gcapped structures by means of specific antibodies after short bromo-uridine (BrU) incorporation. In addition, the sections have been stained by a selective RNA stain, terbium citrate. Our data indicate that perichromatin fibrils incorporate BrU and are labeled by the anti-hybrid probe; this supports the idea that they are the pre-mRNA transcription sites. On the contrary, interchromatin granules do not incorporate BrU after short pulses and are not labeled by the anti-hybrid probe. Concerning the nucleolus, anti-hybrid and anti-BrdU antibodies colocalize only on the dense fibrillar component, suggesting that this is the site of rRNA transcription. Interestingly, the dense fibrillar component and the granular component, after specific RNA staining, show remarkable structural similarities, both containing fibrogranular RNA structures.

Key words: transcription sites, electron microscopy, immunolabeling, terbium, bromo-uridine.

Correspondece: Dr. Marco Biggiogera, Dipartimento di Biologia Animale, Laboratorio di Biologia Cellulare, University of Pavia, Piazza Botta 10, 27100 Pavia, Italy. Phone: international +39.0382.506322. Fax: international +39.0382 506325. E-mail: marcobig@unipv.it

Paper accepted on January 15, 2003

European Journal of Histochemistry 2003; vol. 47 issue 3 [Jul-Sept]: 195-200
RNA transcription has been extensively studied in mammalian cell nuclei for over 30 years at the electron microscope. Since the pioneering work done by Bernhard's group (Fakan and Bernhard, 1971, 1973), EM autoradiography has shown rapid incorporation of $3 \mathrm{H}$-uridine into nascent perichromatin fibrils (PF) at the periphery of condensed chromatin. PF, first described by Bernhard (1969) have hence been indicated as the morphological expression of the pre-mRNA transcription (Fakan, 1994; Misteli and Spector, 1997). It has been demonstrated that there is a direct relationship between PF density and the variation of hnRNA synthetic rate (Fakan and Puvion, 1980). In addition, these components have been also characterized by immunolabeling to contain hnRNPs and snRNPs (Fakan et al., 1984, 1986) thus indicating that PF are indeed sites of transcription and co-transcriptional splicing (Fakan et al., 1984; Mattaj, 1994; Misteli and Spector, 1997; Melcák et al., 2000).

As for rRNA transcription, there has been much debate about the actual site of rDNA location. Briefly, dense fibrillar component (DFC) is considered the actual site of transcription, based on short pulses of $3 \mathrm{H}$-uridine incorporation or after in situ hybridisation (Jimenez-Garcia et al., 1993; Schwarzacher and Wachtler, 1993) as well as DNA localization after Electron Spectroscopic Imaging analysis (Biggiogera et al., 2001). The second hypothesis favours FCs as transcription sites (Thiry and Goessens, 1997) since in this component both RNA polymerase I (Benavente et al., 1988; Raska et al., 1989; Scheer and Benavente, 1990) and rDNA (Thiry and Goessens, 1997) have been shown. A third hypothesis indicates that transcription takes place in regions of DFC close to fibrillar centers (FC) (Risueño and Testillano, 1994; Melcák et al., 1996; Medina et al., 2000).

In this paper, we have used a different approach to visualize transcription sites at electron microscope. We have incorporated bromouridine (BrU) as a pre- 
cursor of RNA into living cells and then revealed it with an anti-BrdU antibody. On the same sections, we have used also an antibody recognizing the DNA/RNA hybrid molecules present at the sites of transcription (Testillano et al., 1994), and stained the sections with terbium, a specific RNA stain (Biggiogera and Fakan, 1998). The aim was to visualize more clearly the sites of transcription in the nucleoplasm and the nucleolus.

\section{Materials and Methods}

\section{Cell culture}

Human fibroblasts from healthy donors at the $10^{\text {th }}-15^{\text {th }}$ passages were used. Cells were grown at low density in D-MEM medium supplemented with $10 \%$ heat-inactivated foetal bovine serum, $20 \mathrm{mM}$ glutamine and 100 units each of streptomycin and penicillin.

BrU incorporation: BrU (Sigma, St. Louis, LO, USA) was given to the cells at a $100 \mu \mathrm{M}$ concentration, dissolved in the cell culture medium, for 5 and $15 \mathrm{~min}$. Cells were then rapidly rinsed in fresh medium, trypsinized and processed for electron microscopy.

Electron microscopy: Fibroblasts, after $\mathrm{BrU}$ incorporation and normal rat liver were fixed with $4 \%$ paraformaldehyde (in Sörensen buffer, $\mathrm{pH} 7.2$ ) for $2 \mathrm{~h}$, at $4^{\circ} \mathrm{C}$, rinsed in Sörensen and dehydrated in ethanol. Fibroblasts were then embedded in LR White, while liver was embedded in Unicryl (according to Scala et al., 1992).

Nickel grids with the sections were incubated for 3 min on Normal Goat Serum (NGS, diluted 1:100 in PBS) and then floated onto a solution of $0.1 \%$ BSA and $0.05 \%$ Tween 20 in PBS (pH 7.4), containing the primary antibody. All the incubations were performed at $4^{\circ} \mathrm{C}$ for $17 \mathrm{~h}$. Some grids were labeled using Tris- $\mathrm{HCl}$ buffer ( $\mathrm{pH}$ 8.5) in the incubation mixture instead of PBS, in order to check for non specific labeling due to the plastic section surface charges (Biggiogera et al., 1990).

Anti-BrdU monoclonal antibody (Becton Dickinson, San Jose', CA, USA, B-44 n. 7580) was used at 1:5 dilution, corresponding to approx. 5 $\mu \mathrm{g} / \mathrm{mL}$. This probe has been proved to cross-react with BrU (Jensen et al., 1993). After rinsing with PBS-Tween and PBS, the grids were incubated with NGS as above. The secondary goat anti-mouse antibody, coupled with $20 \mathrm{~nm}$ colloidal gold
(Jackson Labs., Pennsylvania, USA) was then applied for $30 \mathrm{~min}$ at room temperature at an approx. IgG concentration of $0.3 \mu \mathrm{g} / \mathrm{mL}$.

In some cases, a double labeling was performed by incubating the grids on a mixture containing the anti-BrdU antibody (diluted 1:5) and the rabbit polyclonal anti-m3G capped structures (Lührmann et al., 1982) diluted 1:200 (approx. $6 \mu \mathrm{g} / \mathrm{mL}$ ). After extensive rinsing the grids were incubated with the secondary markers. The goat anti-mouse was coupled to $20 \mathrm{~nm}$ gold, while the goat anti-rabbit was conjugated with $6 \mathrm{~nm}$ gold particles (Jackson Labs).

As for the anti DNA/RNA hybrid, the grids were treated according to Testillano et al. (1994), preincubated with normal rabbit serum (NRS), then the primary antibody was applied at a dilution of 1:100 (approx. $4 \mu \mathrm{g} / \mathrm{mL}$ ). After a second NRS incubation, a rabbit anti-goat probe, conjugated with $20 \mathrm{~nm}$ colloidal gold, diluted 1:20, was used for $30 \mathrm{~min}$ at room temperature.

As controls, some grids were either floated on PBS from which the primary antibody was excluded or were incubated with an unrelated antibody (anti GFAP, glial cell fibrillar acidic protein, Sigma) diluted 1:100, before being processed as above. As an additional control for the antiDNA/RNA hybrid, the sections were pre-treated with 1.5 units/grid of RNase $H$ (Sigma) for $2 \mathrm{~h}$ at $37^{\circ} \mathrm{C}$ (according to Testillano et al., 1994).

All the grids were rinsed with PBS and distilled water, and finally stained as follows.

For selective RNA staining, the grids with the sections were floated onto $0.2 \mathrm{M}$ terbium citrate for Ih at room temperature or at $37^{\circ} \mathrm{C}$, according to Biggiogera and Fakan (1998). Some grids were also stained with the EDTA regressive technique of Bernhard (1969). Stained specimens were observed with a Zeiss EM900 electron microscope equipped with a $30 \mu \mathrm{m}$ objective aperture and operating at $80 \mathrm{kV}$.

\section{Results}

In the control sections, incubated in the absence of the primary antibodies, no labeling was found (not shown).

After labeling with the anti-BrdU antibody, which recognizes $\mathrm{BrU}$ incorporated into newly synthesised RNA, the gold grains can be found at the periphery 


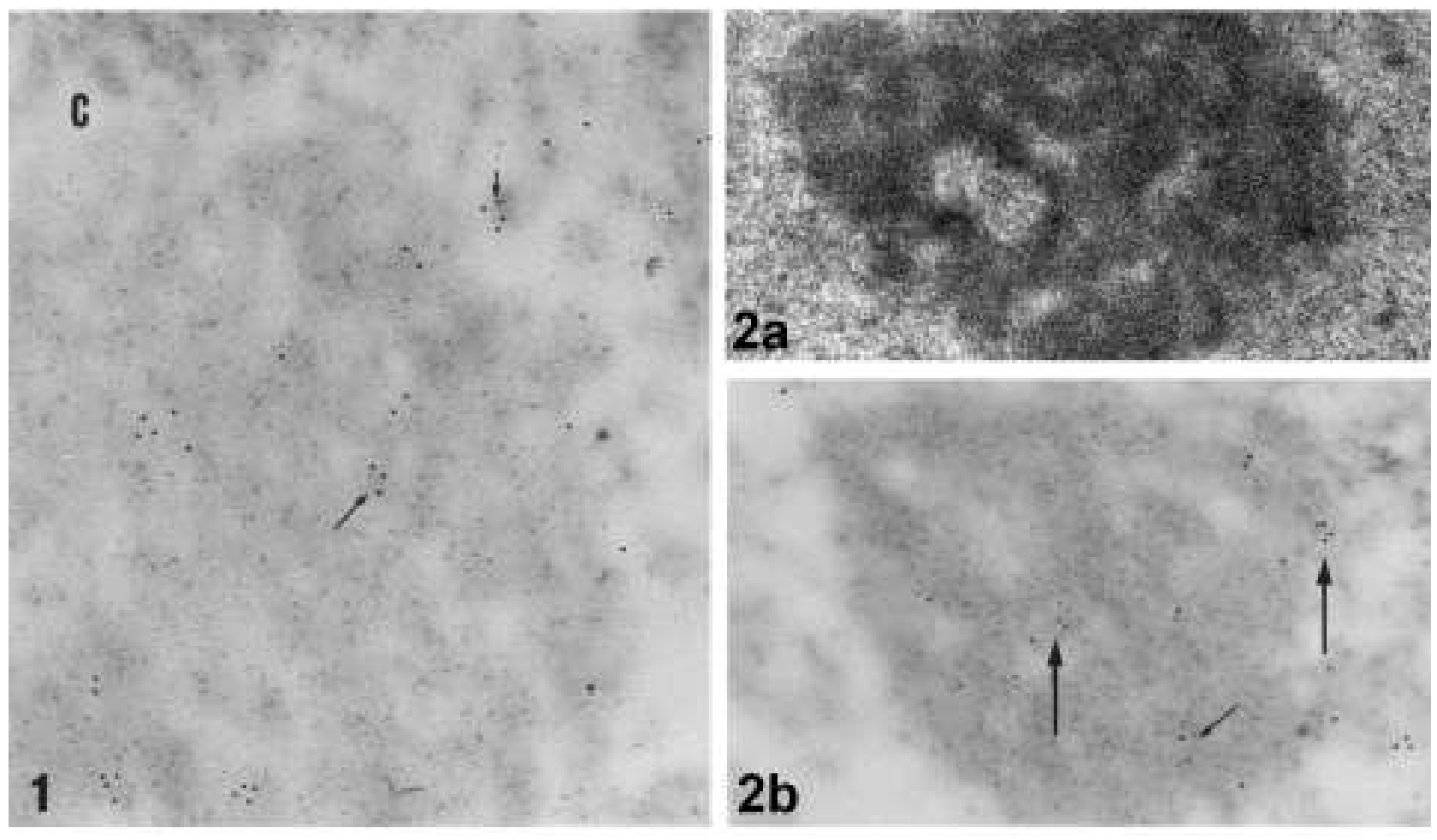

Figure 1. Human fibroblasts after BrU incorporation and selective RNA staining with terbium. The labeling is present on the PF (arrows) at the periphery of condensed chromatin. Note the absence of gold grains on condensed chromatin (c). X68000. Figure 2a. Human fibroblast after conventional preparation (glutraldehyde/osmium fixation and uranyl/lead staining). All the nucleolar components are easily recognizable. $\times 65000$. Figure $2 \mathrm{~b}$. A nucleolus from a $5 \mathrm{~min}$ BrU-labeled fibroblast. Terbium staining. Gold grains representing the sites of BrU incorporation into rRNA are located over the DFC (large arrows) and GC (small arrows). No labeling can be found over FC. Note the fibrogranular appearance of the stained RNA in both DFC and GC. Outside the nucleolus, the labeling is present on PF. X68000.

of the condensed chromatin areas both on liver sections (not shown) and on human fibroblasts (Figure 1 ). The labeling is present on the PF representing newly formed hnRNA. In these conditions, terbium staining allows to visualize selectively the RNA component of the labeled RNP complex.

It is important to note that the labeling, after short pulse of BrU, is absent from the IG clusters, thus underlining the fact that IG are neither sites of transcription nor reached in a short time by $\mathrm{BrU}$ incorporating PF.

An additional remark concerns the possibility that $\mathrm{BrU}$ might be erroneously incorporated into DNA. No gold grains were found on condensed chromatin after BrU detection (Figure 1 ). In addition, in a control experiment, we tried to detect BrU as incorporated BrdU. After hydrolysis and labeling, no gold grains were found on chromatin thus indicating that there is no incorporation into DNA. Moreover, extensive RNase digestion $\left(0.1 \mathrm{mg} / \mathrm{mL}, 24 \mathrm{~h}, 37^{\circ} \mathrm{C}\right) \mathrm{com}$ pletely abolished the labeling (results not shown).

$\mathrm{BrU}$ can obviously be incorporated also into
rRNA. After terbium staining, the nucleolus appears to be quite different; in Figure $2 \mathrm{a}$ is shown a nuclelus after conventional preparation (glutraldehyde/osmium fixation and uranyl/lead staining). The labeling for BrU is present both at the level of the DFC and granular component (GC) (Figure 2b). In addition, no labeling can be found on the FC. Note that after terbium staining, the difference between DFC and GC is not so obvious. RNA can be seen as being present in a sort of fibrogranular form, present in both the locations (Figure 2b).

Anti-hybrid immunolabeling follows essentially the same pattern of $\mathrm{BrU}$ incorporation. In control sections, pre-treated with $\mathrm{RNase} H$, no labeling was found (not shown). PF at the periphery of condensed chromatin and in the interchromatin space are the only structures labeled in the nucleoplasm (Figure 3). IG cluster are always devoid of grains thus once more indicating that IG are not sites of transcription (Figure3, inset).

The DNA/RNA hybrid molecules detected by the 


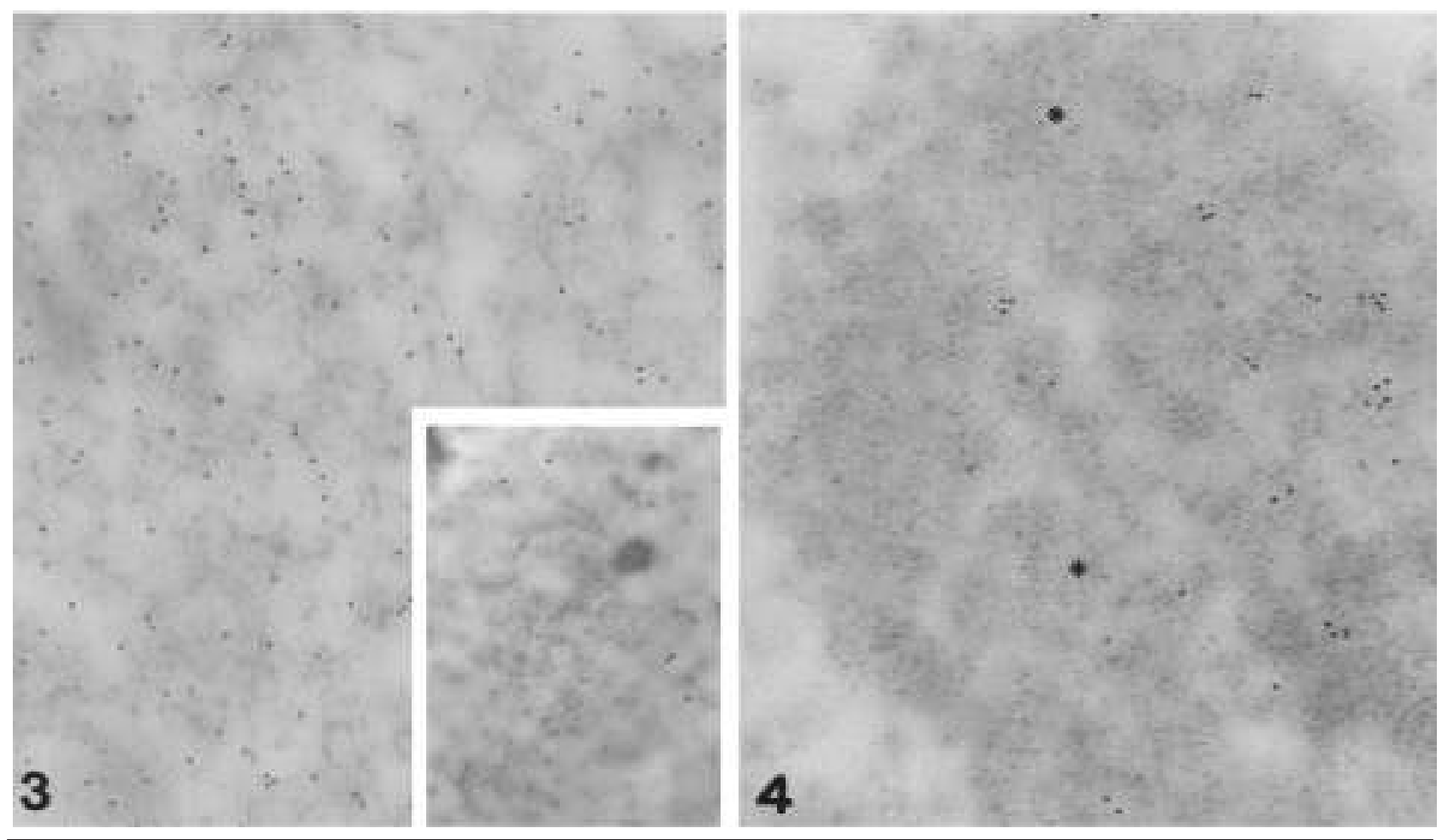

Figure 3. Anti DNA/RNA hybrid labeling on human fibroblast, followed by terbium staining. Labeling is present over the PF in the interchromatin Inset: A cluster of IG not labeled by the antibody. $\times 36000$. Figure 4 . Fibroblast nucleolus, labeling as in Figure 3 and terbium staining. In the nucleolus, the DNA/RNA hybrid molecules are present within the DFC. The gold grains are superimposed onto thin RNA structures. No labeling is present on the GC (asterisks). $\times 68000$

anti-hybrid probe in the nucleolus are present only in the DFC (Figure 4). No labeling can be found either on FC or on the GC.

On hepatocytes, anti-hybrid labeling gives identical results. In Figure 5, a clear nucleoplasmic labeling over $\mathrm{PF}$, is shown.

Single transcription complexes, labelled at their base by the anti-hybrid probe, are presented in Figure $6 \mathrm{a}$ and $6 \mathrm{~b}$ after uranyl or terbium staining, respectively. After double labeling, colocalization of bromine-containing RNA and splicing factors can be seen. In Figure $6 c$ and $d$, newly formed PF, double labeling for BrU (large grains) and $33 \mathrm{G}$ capped RNA structures (small grains) are shown as present on nascent PF.

\section{Discussion}

Our data indicate that:

(i) PF incorporate $\mathrm{BrU}$ and are labeled both by the anti-hybrid probe and anti m3Gcap antibody; they can hence be regarded as the pre-mRNA transcription sites and where co-transcriptional splicing probably takes place; (ii) IG are not sites of tran- scription since they are not labeled by the antihybrid and do not incorporate BrU after short pulse; (iii) anti-hybrid and anti-BrdU colocalize only on the DFC, the pre-rRNA transcription site and (iv) DFC and GC, after specific RNA staining, show remarkable structural similarities, both containing fibrogranular RNA structures. We have characterized the functional sites where transcription and processing take place, combining a specific ultrastructural cytochemical method for RNA with immunogold approaches for visualising labeled structures in the nuclear compartments.

In this paper, we show incorporation of $\mathrm{BrU}$, as well as the localization of the DNA/RNA hybrid molecules, into nascent fibrils of selectively stained RNA.

Our results confirm the data in the literature concerning pre-mRNA transcription (Cmarko et al., 1999, 2000; Risueño and Testillano, 1994; Visa et al. ,1993). Incorporation of BrU occurs at the level of $\mathrm{PF}$ at the border of condensed chromatin and $\mathrm{PF}$ are also labeled by the anti-hybrid probe. $3 \mathrm{H}$ uridine incorporation (after a short pulse) has been also localized in these areas (Fakan and Puvion, 

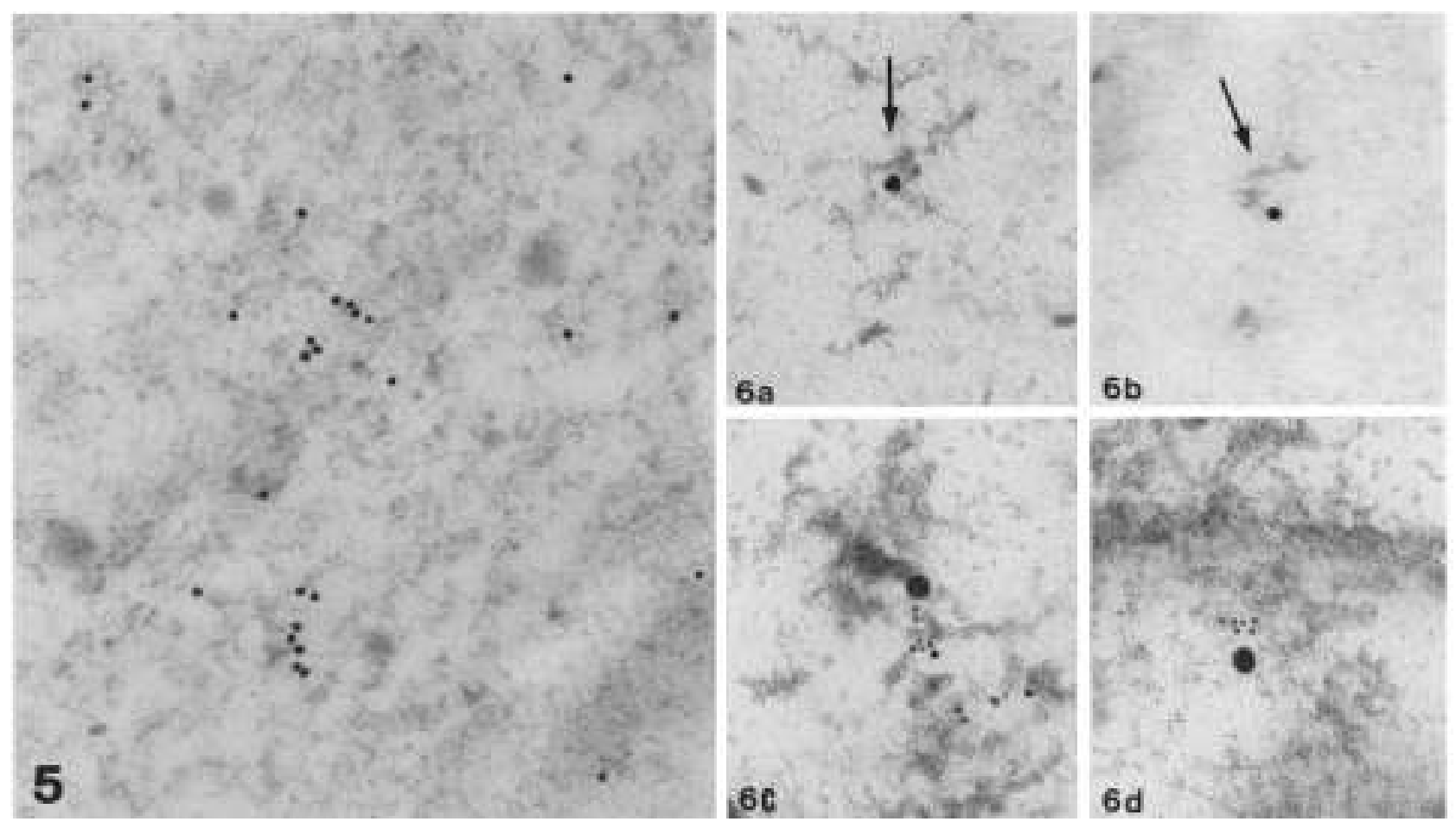

Figure 5. Anti DNA/RNA hybrid labeling and uranyl staining of a rat hepatocyte. The labeling is present on PF. X68000. Figure 6. Single transcription complexes as are shown from rat hepatocyte nuclei. a) DNA/RNA hybrid labeling on a PF (arrows). Uranyl stain. $\times 138000$ b) Same as in a), terbium staining. The arrow indicates the stained RNA within a single PF. $\times 130,000$ c), d) Double labeling for BrU (20nm) and $\mathrm{m3G}$ capped RNA structures (6nm). Co-localization is present over PF. X175,000.

1980). Although BrU takes definitely a longer period to be incorporated significantly (5-15 min compared with the $30 \mathrm{sec}$ pulse of $3 \mathrm{H}$-uridine), is localized in the same areas.

We must underline that, in our conditions, no labeling for BrU was found on chromatin areas, that RNase pretreatment of the sections abolished the labeling and that acid hydrolysis of the sections (necessary to reveal $\mathrm{BrU}$ as possibly being incorporated into DNA, see Wansink et al., 1993) completely abolishes the labeling. These facts indicate that, in our conditions, BrU is incorporated only into RNA and not into DNA. Moreover, we show for the first time selectively stained RNA fibers within a PF labeled for BrU). These data strongly support the idea that BrU is present within RNA only.

Co-localization of BrU and M3G capped structures on PF strongly suggests that, in addition, co-transcriptional splicing might already take place on these structures. Our data are in agreement with the literature (Fakan and Bernhard, 1971; Fakan et al., 1984; Misteli and Spector, 1997, 1998, 1999) and confirm the results of Cmarko and coworkers $(1999,2000)$ after Br-UTP incorporation.

We never obtained BrU labeling on IG clusters or labeling by the anti-hybrid antibody. In this view, we can support the conclusions of other authors reporting that IG are not sites of transcription (Fakan, 1994; Misteli and Spector, 1999).

Concerning the nucleolus, our data indicate that $\mathrm{BrU}$ is mostly localized in the DFC and some labeling is present in the GC. Moreover, the labeling for the DNA/RNA hybrid molecules was found exclusively within the DFC and not in the FCs (Testillano et al., 1994). This would mean that rRNA transcription occurs within the DFC and hence the transcript (already processed?) moves to the GC within the preribosomal particles (see Hozak et al., 1994; Mosgoeller et al., 1998). In the context, it must be noted that some ribosomal proteins such as P1/P2 can be localized already within the DFC (Biggiogera et al., 1990). No labeling for BrU was found within the FCs. All this strongly favours the hypothesis of the DFC as the actual site of rRNA transcription (Hozak, 1995; Biggiogera et al., 2001). Finally, terbium staining for specific RNA localization in the 
nucleus gives some new interesting results. RNA inside PF can be seen as thin fibrils sometimes coiled in one or more parts of the molecule. In the nucleolus, RNA is even more granular, and a very similar structure is found within the DFC and the GC. This fact could be interpreted as due to an already advanced splicing process which occurs in the DFC, so that the RNA molecules leaving this component do not substantially change their shape and length. Interestingly, a similar merging of nucleolar components into one another has been reported in nucleoli from high pressure frozen tissue cryosubstituted in the absence of chemical fixation (Von Schack and Fakan, 1993).

\section{Acknowledgments}

We are indebted to Dr. R. Lührmann for a kind gift of the anti-m3G cap polyclonal antibody. The authors wish to thank Ms. Paola Veneroni for culture cells and treatment.

This work was supported by grants from Italian M.U.R.S.T. (Cofin 2002) and Fondo di Ateneo per la Ricerca.

\section{References}

Benavente R, Reimer G, Rose KM, Hugle-Doerr B, Scheer U. Nucleolar changes after microinjection of antibodies to RNA polymerase I into the nucleus of mammalian cells. Chromosoma 1988;97:115-23.

Bernhard W. A new staining procedure for electron microscopical cytology. J Ultrastruct Res 1969;27:250-65.

Biggiogera M, Fakan S. Fine structural specific visualization of RNA on ultrathin sections. J Histochem Cytochem 1998;46:389-95.

Biggiogera M, Fakan S, Leser G, Martin TE, Gordon JE. Immunoelectron microscopical visualization of ribonucleoproteins in the chromatoid body of mouse spermatids. Mol Repr Dev 1990;26:150-8.

Biggiogera M, Malatesta M, Abolhassani-Dadras S, Amalric F, Rothblum LI, Fakan S. Revealing the unseen: the organizer region of the nucleolus. J Cell Sci 2001;114:3199-205.

Cmarko D, Verschure PJ, Martin TE, Dahmus ME, Krause S, Fu XD, et al. Ultrastructural analysis of transcription and splicing in the cell nucleus after bromo-UTP microinjection. Mol. Biol. Cell 1999; 10:211-23.

Cmarko D, Verschure PJ, Rothblum LI, Hernandez-Verdun D, Amalric $\mathrm{V}$, van Driel $\mathrm{R}$, et al. Últrastructural analysis of nucleolar transcription in cells microinjected with 5-bromo-UTP. Histochem Cell Biol 2000;113:181-7.

Fakan S. Perichromatin fibrils are in situ forms of nascent transcripts. Trends Cell Biol 1994;4:86-90.

Fakan S, Bernhard W. Localization of rapidly and slowly labelled nuclear RNA as visualized by high resolution autoradiography. Exp Cell Res 1971;67:129-41.

Fakan S, Bernhard W. Nuclear labelling after prolonged $3 \mathrm{H}$-uridine incorporation as visualized by high resolution autoradiography. Exp Cell Res 1973;79:431-4.

Fakan S, Puvion E. The ultrastructural visualization of nucleolar and extranucleolar RNA synthesis and distribution. Int Rev Cytol 1980;65:255-99.
Fakan S, Leser G, Martin TE. Ultrastructural distribution of nuclear ribonucleoproteins as visualized by immunocytochemistry on thin sections. J Cell Biol 1984;98:358-63.

Fakan S, Leser G, Martin TE. Immunoelectron microscope visualization of nuclear ribonucleoprotein antigens within spread transcription complexes. J Cell Biol 1986;103:1153-7.

Hozak P. Catching RNA polymerase I in flagranti: ribosomal genes are transcribed in the dense fibrillar component of the nucleolus. Exp Cell Res 1995;216:285-9.

Hozak P, Cook PR. Schöfer C, Mosgöller W, Wachtler F. Site of transcription of ribosomal RNA and intranucleolar structure in $\mathrm{HeLa}$ cells. J Cell Sci 1994;107:639-48.

Jensen PO, Larsen J, Christiansen J, Larsen JK. Flow cytometric measurement of RNA synthesis using bromouridine labelling and bromodeoxyuridine antibodies. Cytometry 1993;14:455-8.

Jimenez-Garcia LF, Segura-Valdez MD, Ochs RL, Echeverria OM, Vazquez-Nin GH, Busch H. Electron microscopic localization of ribosomal DNA in rat liver nucleoli by nonisotopic insitu hybridization. Exp Cell Res 1993;207:220-5.

Lührmann R, Appel B, Bringmann W, Rinke J, Reuter R, Rothe S, et al. Isolation and characterization of rabbit anti-m3G antibodies. Nucleic Acids Res 1982;10:7103-13.

Mattaj IW. RNA processing - splicing in space. Nature 1994;372:7278.

Medina FJ, Cerdido A, de Cárcer G. The functional organization of the nucleolus in plant cells. Eur J Histochem 2000;44:117-31.

Melcák, I, Risueño MC, Raska I. Ultrastructural nonisotopic mapping of nucleolar transcription sites in onion protoplasts. J Struct Biol 1996;116:253-63.

Melcák I, Cermanová S, Jirsová K, Koberna K, Malínsk_J, Raska I. Nuclear pre-mRNA compartmentalization: trafficking of released transcripts to splicing factor reservoirs. Mol Biol Cell 2000; 11:497-510.

Misteli T, Spector DL. Protein phosphorylation and the nuclear organization of pre-mRNA splicing. Trends Cell Biol 1997;7:135-8.

Misteli T, Spector DL. RNA polymerase II targets pre-mRNA splicing factors to transcription sites in vivo. Mol Cell 1999;3:697-705.

Misteli T, Spector DL. The cellular organization of gene expression. Curr Op Cell Biol 1998;10:323-31.

Mosgoeller W, Schöfer C, Wesierska-Gadek J, Steiner M, Müller M, Wachtler F. Ribosomal gene transcription is organized in foci within nucleolar components. Histochem. Cell Biol 1998;109:111-8.

Raska I, Reimer G, Jarnik M, Kostrouch Z, Raska KJ. Does the synthesis of ribosomal RNA takes place within nuclelar fibrillar centers or dense fibrillar components? Biol Cell 1989;65:79-82.

Risueño MC, Testillano PS. Cytochemistry and immunocytochemistry of nucleolar chromatin in plants. Micron 1994;25:331-60.

Scala C, Cenacchi G, Ferrari C, Pasquinelli G, Preda P, Manara GC. A new acrylic resin formulation - a useful tool for histological, ultrastructural, and immunocytochemical investigations. J Histochem Cytochem 1992;40:1799-804.

Scheer $U$, Benavente R. Functional and dynamic aspects of the mammalian nucleolus. BioEssays 1990;12:14-21.

Schwarzacher HG, Wachtler F. The nucleolus. Anat Embryol 1993;188:515-36.

Testillano PL, Gorab E, Risueño MC. A new approach to map transcription sites at the ultrastructural level. J Histochem Cytochem 1994;42:1-10.

Thiry M, Goessens G. The nucleolus during the cell cycle. Springer. New York 1997.

Visa N, Puvion-Dutilleul F, Bachellerie JP, Puvion E. Intranuclear distribution of $U 1$ and $U 2$ snRNAs visualized by high resolution in situ hybridization: revelation of a novel compartment containing UI but not U2 snRNA in HeLa cells. Eur J Cell Biol 1993;60:308-21.

Von Schack ML, Fakan S. The study of the cell nucleus using cryofixation and cryosubstitution. Micron 1993;24:507-19.

Wansink DG, Schul W, Van Der Kraan I, Van Steensel B, Van Driel R, De Jong $L$. Fluorescent labelling of nascent RNA reveals transcription by RNA polimerase II in domains scattered throughout the nucleus. J. Cell Biol 1993;98:358-63. 